\title{
Reflectance of Gray and White Compressed Concrete Paving Units with Different Surfaces
}

\author{
Bin-Feng Yan, Soen-Han Lee, Yu-Hsin Lin \\ Department of Architecture, National Cheng Kung University, No.1, University Road, Tainan City 70101, Taiwan (R.O.C.)
}

\begin{abstract}
This study aims to measure the reflectance of outdoor compressed concrete paving units. The samples are in common size of compressed concrete paving units which is $20 \mathrm{~cm} * 20 \mathrm{~cm} * 6 \mathrm{~cm}$. The first cause of gradually worsening environment is that most of artificial pavements and building shells in the cities are made of materials at low reflectance, so that a large amount of heat energy accumulates inside the materials. In the development of urban environment in Taiwan, the building roofs and artificial pavements account for $80 \%$ of total area of cities. The negative influence of building materials and artificial pavements on the environment is expected to be reduced by improving the utilization of materials at low reflectance. The experimental results of this study showed that the surface roughness of compressed concrete paving units is proportional to the reflectance. When the material surface is smooth, the reflectance of material is high; for rough surface is (e.g. sandblasting, waterproofing), the material reflectance is low. Therefore, it is suggested to use the materials with smooth surface when planning urban paving materials, so as to increase the material reflectance to reduce the urban environment temperature.
\end{abstract}

Keywords-reflectance difference value; flat tile; rustic tile; permeable tile; terrazzo; sandblasted tile.

\section{INTRODUCTION}

With urban development and improvement of living standard, extensive application of air conditioners and relevant facilities, and the development of large area artificial pavements, the living environment is under negative influence, such as greenhouse effect and urban heat island effect. Facing such environmental problems, many measures against environmental problems are developed in buildings, such as restricted use of indoor air conditioning, using high performance thermal insulating building materials, increasing building and peripheral greening and, hoping to reduce and mitigate the deterioration of living environment [1-5]. The thermal characteristics of paved surfaces (albedo, heat capacity, thermal conductivity) interacting with solar radiation are among a number of causal factors affecting UHI, which also include the population and population density of the urban area, building materials, spacing and height of buildings, waste heat generated by vehicles and building equipment, vegetative cover, and geographic location [6$10]$.

Heat islands are caused by urbanization, when buildings, roads and paved surfaces store the sensible heat during the day and then release it slowly during the evening, keeping urban lands hotter than surrounding areas [11]. The urban heat island effect is resulted from the artificial pavements and building shells on urban earth surface which are made of materials at low reflectance, as the materials at low reflectance have thermophysical property of high absorptivity, the materials cannot reflect solar radiation efficiently, so that a great deal of heat energy accumulates inside the materials and is released to the atmospheric environment, not only causing the urban heat island effect, but also influencing the thermal environment factors [12].

However, the outdoor environment deteriorates gradually, the considerations and problems in outdoor environment become one of the key points in current environmental design and planning. This study provides material adoption and suggestion for the future planning and design, hoping to describe and analyze the influence by measuring the reflectance of compressed concrete paving units, so as to provide appropriate ground tile materials for different outdoor environmental conditions.

\section{MATERIALS AND MeTHODS}

\section{A. The study sample}

The study sample size is $20 \mathrm{~cm} * 20 \mathrm{~cm} * 6 \mathrm{~cm}$. The ground tile type is the frequently used type in planning and design, described in Table 1:

TABLE I. THE STUDY SAMPLE

\begin{tabular}{|c|c|c|c|}
\hline Type & Color & Icon & Description \\
\hline Flat tile & $\begin{array}{l}\text { 1. Gray } \\
\text { 2. White }\end{array}$ & & $\begin{array}{l}\text { Basic rectangular compressed concrete paving units, } \\
\text { the compressive strength is } 7200 \mathrm{PSI} \text {, the minimum } \\
\text { water absorption is } 5 \% \text {, customized size is available } \\
\text { in planning and design if there is special demand. }\end{array}$ \\
\hline Permeable tile & Gray & & $\begin{array}{l}\text { The production mode is the same as that of } \\
\text { compressed concrete paving units, the major } \\
\text { differences are the composition and higher water } \\
\text { penetration, the increased permeability coefficient } \\
\text { of surface can be } 1 \times 10^{-2} \mathrm{~cm} / \mathrm{sec} \text {, it can enhance the } \\
\text { water retention ability of strata and contribute to }\end{array}$ \\
\hline
\end{tabular}




\begin{tabular}{|c|c|c|c|}
\hline Type & Color & Icon & Description \\
\hline & & & drainage and temperature control. \\
\hline Rustic tile & & & $\begin{array}{l}\text { The rustic tile is made by using processing } \\
\text { machine to process the overall concrete tile } \\
\text { directly, the finished concrete ground tile has } \\
\text { irregular surface and shape. }\end{array}$ \\
\hline Terrazzo & & & $\begin{array}{l}\text { The terrazzo is the cement product extensively } \\
\text { applied to walls and floors. The cement is mixed } \\
\text { with sand and water, as well as mixing agent and } \\
\text { different crushed stones, crushed powder and paints, } \\
\text { painted on the walls or poured into molds for } \\
\text { forming. }\end{array}$ \\
\hline $\begin{array}{l}\text { Sandblasted } \\
\text { tile }\end{array}$ & White & & $\begin{array}{l}\text { The difference between sandblasted tile and flat } \\
\text { tile is that the sandblasted ground tile is not mixed } \\
\text { with any material in the second surfacing, the } \\
\text { finished surface presents natural rock or rough } \\
\text { surface. }\end{array}$ \\
\hline $\begin{array}{l}\text { Iridescent } \\
\text { crystal } \\
\text { sandblasted } \\
\text { tile }\end{array}$ & & & $\begin{array}{l}\text { The iridescent crystal sandblasted tile is made by } \\
\text { adding waste cullet in the compressed concrete } \\
\text { manufacturing process, the addition follows the } \\
\text { recovered container glass aggregate ( } \psi 1 \sim 3.5 \mathrm{~mm}) \\
\text { under the control of Environmental Protection } \\
\text { Administration. }\end{array}$ \\
\hline
\end{tabular}

\section{B. Research Process}

1) Measurement mold design

According to literature review, the measurement of the reflectance of small-area material is likely to be

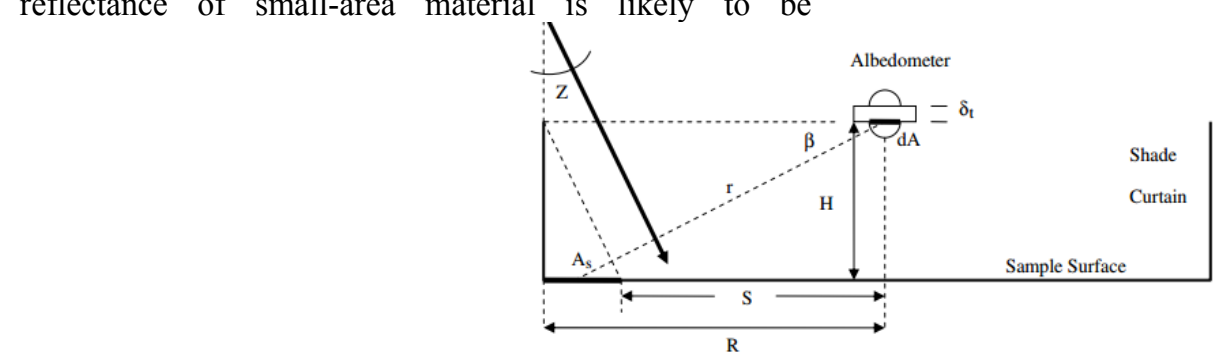

Figure 1. Albedo test stand showing dual pyranometer (albedometer), sample test influenced by ambient environment. A measurement aiding tool screening external environment is made referring to the experimental design of David J.Sailor [13], Fig. 1.
The actinographs were mounted above the test samples, one set pointed upwards to the sky $I_{H}$, the other set was aligned downwards with the white standard sample $I_{W}$, black standard sample $I_{b}$ and test sample $I_{t}$. The data of the two actinographs were read at the same time, one was divided by the other to obtain the albedo, which were $A^{\prime}{ }_{w}, A^{\prime}{ }_{b}$ and $A^{\prime}{ }_{t}$. The albedometer used in this study was a two-way, which could measure the solar radiation quantity and sample reflectance simultaneously, increasing the accuracy.

The double-actinograph measurement method is described below:

$$
\begin{aligned}
A^{\prime}{ }_{t} & =\frac{I_{t}}{I_{H t}} \\
A^{\prime}{ }_{b} & =\frac{I_{b}}{I_{H b}} \\
A^{\prime}{ }_{w} & =\frac{I_{w}}{I_{H w}}
\end{aligned}
$$

After equation transposition

$$
\frac{I}{I_{H}}=A \times F+A_{e}, \mathrm{x}(1-F)
$$

Consequently,

$$
\begin{aligned}
& \frac{I_{w}}{I_{H w}}=A_{w} \times F+A_{e}, \mathrm{x}(1-F) \\
& \frac{I_{b}}{I_{H b}}=A_{b} \times F+A_{e}, \mathrm{x}(1-F) \\
& \frac{I_{t}}{I_{H t}}=A_{t} \times F+A_{e}, \mathrm{x}(1-F)
\end{aligned}
$$

According to the aforesaid two terms

$$
\frac{I_{w}}{I_{H w}}-\frac{I_{b}}{I_{H b}}=\left(A_{w}-A_{b}\right) \times F
$$

Substituted in the aforesaid equation

$$
A^{\prime}{ }_{w}-A^{\prime}{ }_{b}=\left(A_{w}-A_{b}\right) \times F
$$

Substituted in the aforesaid equation

$$
A^{\prime}{ }_{t}-A^{\prime}{ }_{b}=\left(A_{t}-A_{b}\right) \times F
$$


Substituted in the aforesaid equation

$$
A_{t}=A_{b} \frac{A^{\prime} t^{-A \prime} b}{A^{\prime} w^{-}-A_{b}^{\prime}}\left(A_{w}-A_{b}\right)
$$

\section{RESULTS}

A. Reflectance of gray and white samples in summer.

The first summer samples are classified into gray flat tile (control group: white flat tile), permeable tile (control group: gray flat tile), rustic tile (control group: gray flat tile). Figure 2 shows that the reflectance difference values of gray ground tiles are in explicit sequence, the control group of gray flat tile is white flat tile, so the difference value is highest. The average reflectance of control group of gray ground tile samples (gray flat tile) is 28 to $38 \%$. Among the gray sample ground tiles in this study, the difference value of permeable tile is 13 to $16 \%$, the difference value of rustic tile is -4 to $-7 \%$.

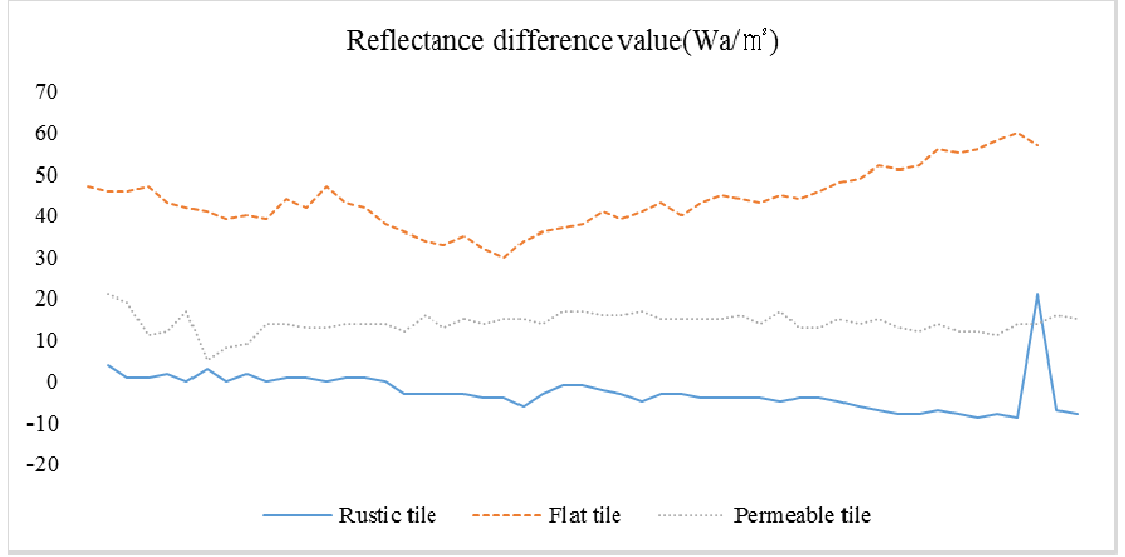

Figure 2. Summer gray samples' reflectance difference value change chart.

The second summer samples of this study are classified into white flat tiles, iridescent crystal sandblasted tiles, sandblasted tiles, and terrazzo tiles. The control group is white flat tile. Figure 3 shows the reflectance of sample ground tiles is sequenced according to the difference value, larger difference value represents lower reflectance of the samples of experimental group (lower than control group). The average reflectance of control group (white flat tiles) of various sample ground tiles is 70 to $83 \%$.

Among the white sample ground tiles of this study, the terrazzo tile has the maximum difference in reflectance in summer ( 36 to $47 \%$ ), followed by the sandblasted tile ( 28 to $39 \%$ ), while the iridescent crystal sandblasted tile has the minimum difference value (5 to $6 \%$ ).

\section{Reflectance difference value $\left(\mathrm{Wa} / \mathrm{m}^{2}\right)$}

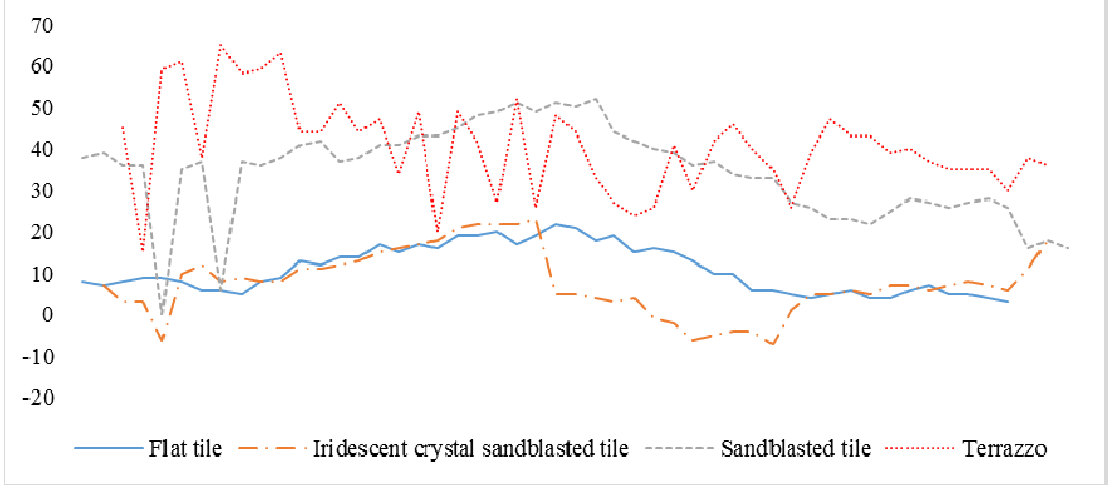

Figure 3 Summer white samples' reflectance difference value change chart.

\section{B. Reflectance of gray and white samples in winter.}

The first winter samples are classified into gray flat tile (control group: white flat tile), permeable tile (control group: gray flat tile), rustic tile (control group: gray flat tile). Figure 4 shows that the average reflectance of control group gray flat tile of various sample ground tiles is 24 to $35 \%$. 


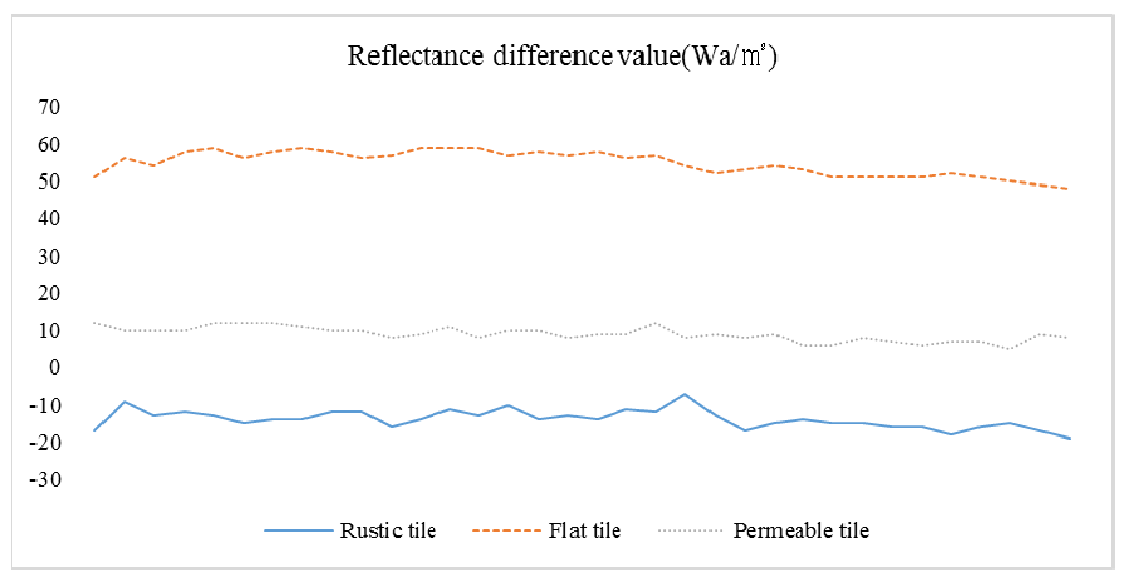

Figure 4. Winter gray samples' reflectance difference value change chart.

Among the gray sample ground tiles in this study, the reflectance difference value of permeable tile is 11 to $12 \%$, the reflectance difference value of rustic tile is -15 to $16 \%$. The second winder samples of this study are classified into flat tile, iridescent crystal sandblasted tile, sandblasted tile, and terrazzo tile. The control group is white flat tile. Figure 5 shows the average reflectance of control group (white flat tile) of various sample ground tiles is 81 to $84 \%$.

Reflectance differencevalue $\left(\mathrm{Wa} / \mathrm{m}^{2}\right)$

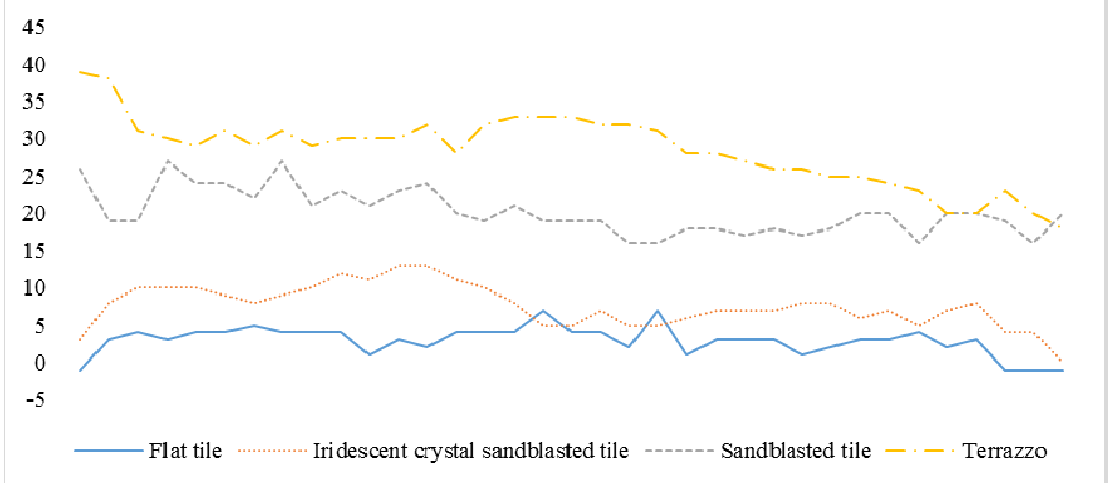

Figure 5. Winter samples' reflectance difference value change chart.

Among the sample ground tiles of this study, the terrazzo tile has the maximum difference in reflectance in winter (27 to $28 \%$ ), followed by the sandblasted tile (20 to $16 \%$ ), while the iridescent crystal sandblasted tile has the minimum difference value ( 7 to $8 \%$ ).

\section{CONCLUSIONS}

The experimental results show that the rustic tile has maximum reflectance, which is $33-41 \mathrm{~W} / \mathrm{m}^{2}$, about 4 $16 \mathrm{~W} / \mathrm{m}^{2}$ higher than control group (gray flat tile). The reflectance of gray flat tile is $34-38 \mathrm{~W} / \mathrm{m}^{2}$, and the permeable tile has the minimum reflectance, which is 6$9 \mathrm{~W} / \mathrm{m}^{2}$, about $11-12 \mathrm{~W} / \mathrm{m}^{2}$ lower than control group (gray flat tile). It is found in this study that for the white samples, the addition of waste glass has unobvious effect on increasing the reflectance of samples. In terms of iridescent crystal sandblasted tile, the reflectance of white flat tile of control group without any admixture is 71-82 $\mathrm{W} / \mathrm{m}^{2}$. However, after the iridescent crystal (waste glass) is added, the reflectance of sample is reduced by 5-6 $\mathrm{W} / \mathrm{m}^{2}$. The findings show that when the flat tile becomes rustic tile after surface treatment, the sample's reflectance is increased. Because the rustic tile is mixed with a little iridescent crystal component, the iridescent crystal component adheres to the surface after the surface is processed, so that the reflectance is increased.

Another permeable tile sample measurement result shows that the permeable tile has large surface pores after the surface of flat tile sample is processed, so that the surface reflectivity declines, and the reflectance decreases obviously. To sum up, the surface roughness of compressed concrete paving units is proportional to the reflectance. When the material surface is smooth, the reflectance of material is high; while for a rough surface 
(e.g. sandblasting, waterproofing), the material reflectance is low. Therefore, it is suggested to use the materials with smooth surface in planning urban paving materials, so as to increase the material reflectance to reduce urban environment temperature.

\section{REFERENCES}

11] Racine, T. A. P. \& Fabianal, L. F., Measurement of albedo and analysis of its influence the surface. Energy and Buildings, 37, pp.295-300, 2005

[2] Li, H., Harvry, J. \& Jones, D. Field measurement of albedo for different land cover materials and effectson thermal performance. Building and Environment, 59, pp.1-11, 2013.

[3] Haider, T. Urban climates and heat islands: albedo, evapotranspiration, and anthropogenic heat. Energy and Buildings, 25, pp.99-103, 1997.

[4] Yu, B. F., Chen, Z. \& Shang, P. J. Study on the influence of albedo on building heat environment in a year-round. Energy and Buildings, 40, PP.945-951, 2008

[5] David, J. S., Kyle, R. \& Del, S. Field measurement of albedo for limited extent test surfaces. Solar Energy, 80, pp.589-599, 2006.

[6] Hashem, A. \& Damon, M. Global cooling updates: reflective roofs and pavements. Energy and Build, 55, pp.2-6, 2012.
[7] Jo, J. H., Carlson, J. D., Golden, J. S. \& Bryan, H. An integrated empirical and modeling methodology for analyzing solar reflective roof technologies on commercial buildings. Building and Environment, 45, pp.453-460, 2010.

[8] Takashi, A. \& Vu, T. A. Characteristics of permeable pavement during hot summer weather and impact on the thermal environment. Building and Environment, 35, pp.363-375, 2000.

[9] Synnefa, A., Karlassi, T., Gaitani, N., Santamouris, M., Assimakopoulos, D. N. \& Papakatsikas. Experimental testing of cool colored thin layer asphalt and estimation of its potential to improve the urban microclimate. Building and Environment, 46, pp.38-44, 2011.

[10] Santamouris, M., Gaitani, N., Spanou, A., Saliari, M., Giannopoulou, K. \& Vasilakopoulou, K. Using cool paving materials to improve microclimate of urban areas - design realization and results of the flisvos project. Building and Environment, 53, pp.128-136, 2012.

[11] Jusuf, S. K., Wong, N. H., Hagen E., Anggoro, R. \& Hong, Y. The influence of land use on the urban heat island in Singapore. Habitat Int., 31, pp.232-242, 2007.

[12] Huang, Y. S. The Effect of Material Composition on Concrete Albedo. Kaohsiung: I-Shou University, 2010.

[13] David, J. S., Kyle, R. \& Del, S. Field measurement of albedo for limited extent test surfaces. Solar Energy, 80, pp.589-599, 2006. 